\title{
ПУТИ ПОВЫШЕНИЯ ЭФФЕКТИВНОСТИ ИСПОЛЬЗОВАНИЯ ОСНОВНЫХ СРЕДСТВ
}

\section{(C) 2019 Вахрушева Наталья Александровна}

кандидат экономических наук,

доцент кафедры Экономической теории и анализа, Экономический факультет

Стерлитамакский филиал Башкирского Государственного Университета, Респ. Башкортостан, Уфа

В статье проводится анализ использования основных средств АО «МК «Витязь» за период 20152017 годов. На основе проведенного исследования разрабатываются рекомендации повышения эффективности использования основных средств компании и проводится оценка целесообразности предложенных рекомендаций.

Ключевые слова: основные средства, коэффициент обновления, коэффициент выбытия, срок обновления, коэффициент износа, коэффициент технической годности, активная часть основных средств, фондоотдача, фондоемкость, фондорентабельность, фондовооруженность.

В настоящее время в условиях жесткой конкуренции все хозяйствующие субъекты нацелены на повышение эффективности своей деятельности. Одним из направлений повышения эффективности деятельности является поиск резервов роста эффективности использования основных средств. Эффективное использование основных средств способствует повышению конечных результатов деятельности организации.

Предприятие использует основные средства продолжительное время, более одного года, перенося свою стоимость на стоимость готовой продукции в течении срока его полезного использования. Как правило, существуют две основные проблемы, стоящие на пути эффективного использования основных средств: эксплуатация основных средств без обновления продолжительное время; постоянное обновление оборудования без надлежащего обоснования с экономической точки зрения.

Первая проблема приводит к снижению конкурентоспособности компании по инновационной составляющей, а вторая к недополучению прибыли в связи с потерей конкурентоспособности по ценовому признаку.
Поэтому в настоящее время повышение эффективности использования основных средств имеет особое значение для многих компаний, так как позволяет ускорить их оборачиваемость, сократить разрыв в сроках физического и морального износа, ускорить темпы обновления основных средств.

Актуальность темы исследования заключается в том, что на современном этапе развития экономики проблема эффективности использования основных средств приобретает особую значимость, поскольку истинная оценка использования основных средств предприятия позволяет наиболее эффективно ими управлять и влиять на результат деятельности в целом.

Акционерное общество «Машиностроительная компания «Витязь» является одним из мировых лидеров по производству наземных транспортных средств высокой проходимости, предназначенных для перевозки грузов и людей в особо сложных дорожных и климатических условиях.

Проведем анализ движения и технического состояния основных средств АО «МК «Витязь» за период 2016-2017 гг (см. табл. 1).

Таблица 1. Анализ движения и технического состояния основных средств

\begin{tabular}{|l|c|c|c|}
\hline \multicolumn{1}{|c|}{ Показатель } & 2016 & 2017 & Изменение, $(+,-)$ \\
\hline Коэффициент обновления & 0,02 & 0,04 & 0,02 \\
\hline Срок обновления & 65,92 & 28,90 & $-37,02$ \\
\hline Коэффициент выбытия & 0,02 & 0,02 & - \\
\hline Коэффициент износа & 0,34 & 0,40 & 0,05 \\
\hline Коэффициент технической годности & 0,65 & 0,61 & $-0,04$ \\
\hline
\end{tabular}


Анализ движения и технического состояния основных средств АО «МК «Витязь» показал, что доля новых основных средств в общей их стоимости снизилась на 0,02 , что указывает на обновления основных средств, однако за счет роста износа стоимость основных средств сокращается.

Снижение срока обновления в 2017 году на 37,02 отражает уменьшение среднего срока обновления основных средств и оценивается как положительная тенденция. Поскольку коэффициент выбытия меньше коэффициента обновления, то на $\mathrm{AO}$ «МК «Витязь» наблюдается процесс обновления основных фондов.

Рост коэффициента износа в 2017 году является негативной тенденцией и указывает на повышение доли изношенных основных средств и ухудшение их технического состояния.

Коэффициент технической годности в 2017 году снижается на 0,04 , что оценивается как отрицательная тенденция, поскольку указывает на ухудшение технического состояния основных средств.

Таким образом, в целом состояние основных средств $\mathrm{AO}$ «МК «Витязь» находится в пригодном для использования состоянии. Для увеличения эффективности их использования, необходимо чтобы устаревшие основные средства регулярно списывались. На данный момент доля выбывших основных средств крайне мала, о чем гово- рит коэффициент выбытия, значение составляет $2 \%$. Значение коэффициента годности указывает на ухудшение технического состояния основных средств. Если в ближайшие несколько лет будет продолжать увеличиваться износ оборудования, то снизится выпуск готовой продукции и производительность труда, что приведет к негативным последствиям.

Проведем оценку эффективности использования основных фондов АО «МК «Витязь» за период 2015-2017 годов с учетом изменения темпов объема реализации продукции предприятия.

В таблице 2 представим исходные данные для оценки эффективности использования основных фондов АО «МК «Витязь».

Исходные данные для оценки эффективности использования основных фондов АО «МК «Витязь» свидетельствуют о том, что в 2016 году стоимость основных фондов сократилась на 12946 тыс.руб. или на 7,69\% и в 2017 году на 9735 тыс.рублей или на 6,26\% преимущественно за счет начисления амортизации.

Стоимость активной части основных фондов производства, включающую машины, оборудование и транспортные средства на протяжении всего анализируемого периода имеет отрицательную динамику, так в 2016 году сокращается на 18,12\% или 10068 тыс.руб., а в 2017 году на 6908 тыс.рублей или на 15,19\%. Сокращение доли активной части основных фондов является

Таблица 2. Исходные данные для оценки эффективности использования основных фондов $\mathrm{AO}$ «МК «Витязь»

\begin{tabular}{|l|c|c|c|c|c|c|c|}
\hline \multicolumn{1}{|c|}{ Показатель } & \multicolumn{3}{|c|}{ Год } & \multicolumn{4}{c|}{ Изменения } \\
\cline { 2 - 8 } & 2015 & 2016 & 2017 & \multicolumn{2}{|c|}{ Абсолютное, + Относительное, \% } \\
\cline { 4 - 8 } & & & 2016 к & $\begin{array}{c}2017 \text { к } \\
2016\end{array}$ & $\begin{array}{c}2016 \text { к } \\
2015\end{array}$ & $\begin{array}{c}2017 \text { к } \\
2016\end{array}$ \\
\hline $\begin{array}{l}\text { 1. Стоимость основных фондов, } \\
\text { тыс.руб. }\end{array}$ & 168423 & 155477 & 145742 & -12946 & -9735 & 92,31 & 93,74 \\
\hline $\begin{array}{l}\text { 2. Стоимость активной части } \\
\text { основных фондов, тыс.руб. }\end{array}$ & 55554 & 45486 & 38578 & -10068 & -6908 & 81,88 & 84,81 \\
\hline $\begin{array}{l}\text { 3. Выручка от реализации про- } \\
\text { дукции, тыс.руб. }\end{array}$ & 676267 & 650032 & 671757 & -26235 & 21725 & 96,12 & 103,34 \\
\hline $\begin{array}{l}\text { 4. Прибыль от реализации про- } \\
\text { дукции, тыс.руб. }\end{array}$ & 67675 & 62175 & 59344 & -5500 & -2831 & 91,87 & 95,45 \\
\hline 5. Численность персонала & 1389 & 1337 & 1442 & -52 & 105 & 96,26 & 107,85 \\
\hline $\begin{array}{l}\text { б.Среднегодовая стоимость } \\
\text { основных фондов, тыс.руб. }\end{array}$ & 158370 & 161950 & 150610 & 3580 & -11340 & 102,26 & 93,00 \\
\hline $\begin{array}{l}\text { 7. Удельный вес активной части } \\
\text { основных средств }\end{array}$ & 0,3298 & 0,2926 & 0,2647 & $-0,0373$ & $-0,0279$ & - & - \\
\hline $\begin{array}{l}\text { 8. Удельный вес оборудования } \\
\text { в активной части основных } \\
\text { средств }\end{array}$ & 0,6062 & 0,9863 & 0,9681 & 0,3802 & $-0,0182$ & - & - \\
\hline
\end{tabular}


отрицательной тенденцией.

Относительное отклонение стоимости основных фондов в 2016 году составило:

ОФОТн $=155477-168423 \times 650032 / 676267=$ -6412 тыс.руб.

Таким образом, в 2016 году АО «МК «Витязь» получило относительную экономию в размере 6412 тыс.руб.

Относительное отклонение стоимости основных фондов в 2017 году составило:

ОФотн $=145742-155477 \times 671757 / 650032=$ -14776 тыс.руб.

Таким образом, в 2017 году АО «МК «Витязь» получило относительную экономию в размере 14776 тыс.руб. за счет эффективного использования основных фондов, в том числе за счет роста выручки от реализации на $3,34 \%$.

Проведем анализ эффективности использования основных фондов АО «МК «Витязь» за период 2015-2017 годов на основе таких показателей как: фондоотдача, фондоемкость, фондорентабельность и фондовооруженность (см. табл. 3).

Из таблицы 3 видно, что фондоотдача основных средств снизилась в 2016 году на 0,26 , а в 2017 году увеличилась на 11,22\%, что указывает на повышение эффективности использования основных средств производства, поскольку в 2017 году на 44 копейки увеличилась выручка с каждого вложенного рубля в основные фонды $\mathrm{AO}$ «МК «Витязь».

Фондоотдача оборудования в 2016 году увеличилась на 2,12 и в 2017 году на 3,12, что указывает на повышение эффективности использования оборудования.
Фондоемкость в 2016 году увеличилась на 0,01 или на $6,39 \%$ и в 2017 году снизилась на 0,02 или на $10,01 \%$, что также свидетельствует о повышении эффективности использования основных фондов в 2017 году, поскольку на обеспечение производства единицы продукции или на каждый рубль выручки от реализации приходилось на 2 копейки меньше в 2017 году стоимости основных фондов.

Показатель фондовооруженности АО «МК «Витязь» в 2016 году растет на 6,24\% преимущественно за счет сокращения численности сотрудников, а в 2017 году сокращается на 13,77\% или на 16,68 за счет роста численности персонала, что свидетельствует о снижении уровня оснащенности труда основными средствами.

Фондорентабельность рассчитанная по чистой прибыли снижается в 2015-2017 годах, что свидетельствует о снижении уровня эффективности использования основных фондов $\mathrm{AO}$ «МК «Витязь» в процессе своей деятельности, а рост ее в 2017 году говорит, напротив, о повышении эффективности использования основных фондов предприятия. Так, фондорентабельность рассчитанная с учетом чистой прибыли снизилась в 2016 году на 2,75 и составила всего 0,16\%, а в 2017 году на 0,06 и составила $0,1 \%$.

Фондорентабельность, рассчитанная по прибыли от реализации в 2016 году снизилась на 4,34 и составила 38,39\%, а в 2017 году незначительно возросла на $1,01 \%$ и составила $39,40 \%$ за счет роста выручки на $3,34 \%$.

Снижение эффективности использования основных фондов АО «МК «Витязь» обусловлено снижением прибыли от реализации и чистой

Таблица 3. Анализ показателей эффективности использования основных фондов АО «МК «Витязы»

\begin{tabular}{|c|c|c|c|c|c|c|c|}
\hline \multirow{3}{*}{ Показатель } & \multicolumn{3}{|c|}{ Год } & \multicolumn{4}{|c|}{ Изменения } \\
\hline & \multirow[b]{2}{*}{2015} & \multirow[b]{2}{*}{2016} & \multirow[b]{2}{*}{2017} & \multicolumn{2}{|c|}{ Абсолютное, (+,-) } & \multicolumn{2}{|c|}{ Относительное, \% } \\
\hline & & & & $\begin{array}{c}2016 \mathrm{~K} \\
2015\end{array}$ & $\begin{array}{c}2017 \mathrm{k} \\
2016\end{array}$ & $\begin{array}{c}2016 \mathrm{~K} \\
2015\end{array}$ & $\begin{array}{c}2017 \mathrm{k} \\
2016\end{array}$ \\
\hline Фондоотдача & 4,27 & 4,02 & 4,46 & $-0,26$ & 0,44 & 94,00 & 111,22 \\
\hline Фондоотдача оборудования & 12,17 & 14,29 & 17,41 & 2,12 & 3,12 & 117,40 & 121,85 \\
\hline Фондоемкость & 0,23 & 0,25 & 0,22 & 0,01 & $-0,02$ & 106,39 & 89,99 \\
\hline Фондовооруженность. & 114,02 & 121,13 & 104,45 & 7,11 & $-16,68$ & 106,24 & 86,23 \\
\hline $\begin{array}{l}\text { Фондорентабельность (при- } \\
\text { быль от реализации на } 1 \text { рубль } \\
\text { среднегодовой стоимости } \\
\text { основных фондов) }\end{array}$ & 42,73 & 38,39 & 39,40 & $-4,34$ & 1,01 & 89,84 & 102,63 \\
\hline $\begin{array}{l}\text { Фондорентабельность (чистая } \\
\text { прибыль на } 1 \text { рубль средне- } \\
\text { годовой стоимости основных } \\
\text { фондов) }\end{array}$ & 2,91 & 0,16 & 0,10 & $-2,75$ & $-0,06$ & 5,49 & 61,86 \\
\hline
\end{tabular}


прибыли в 2016 и 2017 годах.

Оценим влияние изменения выручки от реализации продукции и стоимости основных фондов на снижение фондоотдачи. Исходные данные приведены в таблице 3.

1) Определим значение показателя фондоотдачи в 2016 году: ФО2016 = $650032 / 161950=4,01$;

2) Определим значение показателя фондоотдачи в 2017 году: ФО2017 = $671757 / 150610=4,46$;

3) Рассчитаем изменение фондоотдачи: $\Delta \Phi О=4,46-4,01=0,45$;

4) Рассчитаем темп прироста фондоотдачи: Тпр (ФО) = 0,45 / 4,01 х 100\% = 11,22\%;

Фондоотдача увеличилась за 2017 год на $11,22 \%$;

5) Рассчитаем влияние изменения выручки от реализации продукции на изменение фондоотдачи $\triangle Ф О(\mathrm{~B})$ :

$\Delta \Phi O(\mathrm{~B})=(671757-650032) / 161950=0,13$

Рост выручки на 21725 тыс.руб. привел к росту фондоотдачи на 0,13.

6) Рассчитаем влияние изменения среднегодовой стоимости основных фондов на изменение фондоотдачи $\triangle Ф О(Ф О):$

$\Delta \Phi О(Ф О)=[671757 / 150610-671757 / 161950]=0,32$

Следовательно, сокращения среднегодовой стоимости основных средств на 11340 тыс.руб. привело к росту фондоотдачи на 0,32 .

Таким образом, под влиянием роста выручки от реализации на 21725 тыс.руб. и снижения среднегодовой стоимости основных средств на 11340 тыс.руб. фондоотдача увеличилась в целом на $0,45(0,13+0,32)$.

Рассчитаем влияние факторов на рентабельность основных средств $\left(R_{0 c}\right)$, с помощью метода абсолютных разниц:

1) Рассчитаем изменения рентабельности за счет чистой прибыли $\Delta \mathrm{R}_{\mathrm{OC}}$ (ЧП):

$\Delta \mathrm{R}_{\mathrm{OC}}($ ЧП $)=(0,0222-0,0398) \times 4,01=-0,07$.

Снижение чистой прибыли практически в 2 раза привело к снижению рентабельности основных средств на 0,07 .

2) Рассчитаем влияние изменения рентабельности за счет фондоотдачи $\Delta \mathrm{R}_{\mathrm{OC}}(Ф \mathrm{O})$ :

$\Delta \mathrm{R}_{\mathrm{OC}}(Ф \mathrm{O})=0,0222 \times(4,46-4,01)=0,01$.

Рост фондоотдачи на 0,45 способствовал росту рентабельности основных средств на 0,01 .

Таким образом, рост фондоотдачи на 0,45 и снижение чистой прибыли на $42,47 \%$ привели к снижению рентабельности основных средств на
0,06 в 2017 году $(-0,07+0,01=-0,06)$.

Оценим влияние удельного веса активной части основных фондов, удельного веса оборудования в стоимости активной части основных фондов и фондоотдачи оборудования, используя мультипликативную трехфакторную модель с применением метода абсолютных разниц:

$\Delta \Phi \mathrm{O}_{\mathrm{yBa}}=\Delta \mathrm{yB}_{\mathrm{a}} * \mathrm{yB}_{\mathrm{о}} 0 * \Phi^{0} \mathrm{O}^{0}=(-0,0279) *$ $0,9863 * 14,29=-0,39$;

$\Delta \Phi \mathrm{O}_{\mathrm{yвоб}}=\mathrm{yB}_{\mathrm{a} 0} * \Delta \mathrm{VB}_{\text {об }} *{\Phi \mathrm{O}^{\circ} 0}=0,2926$ * $(-0,0182) * 14,29=-0,07$;

$\Delta \Phi \mathrm{O}_{\Phi \text { Ооб }}=\mathrm{yB}_{\mathrm{a} 0} * \mathrm{yB}_{\mathrm{0б} 0} * \Delta \Phi \mathrm{O}_{\text {об }}=0,2926 *$ $0,9863 * 3,12=0,90$;

$$
\Delta \Phi \mathrm{O}=\Delta \Phi \mathrm{O}_{\mathrm{УBa}}+\Delta \Phi \mathrm{O}_{\text {Увоб }}+\Delta \Phi \mathrm{O}_{\text {Фооб }}=0,44 .
$$

В 2017 году фондоотдача увеличилась на 0,44 за счет влияния следующих факторов:

- положительно повлиял рост фондоотдачи оборудования за счет чего фондоотдача увеличилась на 0,90 ;

- отрицательное влияние оказали снижение удельного веса активной части в основных средствах и удельного веса оборудования в активной части основных средств, что привело к снижению фондоотдачи в совокупности на 0,46.

Таким образом, среди позитивных тенденций, выявленных в ходе анализа и оценки использования основных средств АО «МК «Витязь» следует отметить:

1) рост фондоотдачи основных средств и оборудования, снижение фондоемкости в 2017 году указывает на повышение эффективности использования основных средств за счет роста выручки и снижения среднегодовой стоимости основных средств;

2) в структуре основных средств основную долю занимают здания и рабочие машины и оборудование;

3) коэффициент выбытия меньше коэффициента обновления, что указывает на расширенное воспроизводство основных фондов.

В качестве выявленных отклонений в ходе анализа и оценки использования основных средств $\mathrm{AO}$ «МК «Витязь» следует отметить:

1) снижение фондорентабельности основных средств по чистой прибыли;

2) снижение фондовооруженности;

3) повышение износа основных средств. 
Следовательно, в целях повышения эффективности использования основных средств ОА «МК «Витязь» необходимо реализовать следующие меры:

1) снизить износ основных средств за счет сокращения степени их износа и обновления;

2) повысить фондовооруженность за счет оптимизации численности персонала, которая положительно отразиться на финансовых результатах деятельности за счет сокращения затрат на оплату труда;

3) повысить фондорентабельность основных средств за счет роста прибыльности предприятия.

Следовательно, в целях повышения эффективности деятельности ОА «МК «Витязь» необходимо снизить зависимость от внешних источников финансирования путем погашения планомерного погашения долгосрочных и краткосрочных обязательств предприятия, нара- щивать объемы реализации, снижать расходы, увеличивать прибыль и оптимизировать численность персонала.

С целью снижения износа основных средств целесообразно осуществлять обновление основных средств, используя в качестве основного источника финансирования лизинг с отражением на балансе лизингодателя приобретаемых основных средств, т.к. именно этот способ позволяет обеспечить экономию по налогу на прибыль, налогу на добавленную стоимость и налогу на имущество. При этом, использование лизинга при приобретении основных средств позволяет применять ускоренную амортизацию, что обеспечивает дополнительную экономию по налогу на имущество.

Таким образом, предложенные пути обеспечат $\mathrm{AO}$ «МК «Витязь» повышение эффективности использования основных средств.

\section{Библиографический список}

1. Герасимова В.В. Экономическое содержание основных средств // Молодой ученый. - 2016. - № 2.- С. 451459.

2. Турманидзе, Т. У. Финансовый анализ [Электронный ресурс]: учебник для студентов вузов, обучающихся по экономическим специальностям / Т.У. Турманидзе.- 2-е изд., перераб. и доп.- М.: ЮНИТИДАНА, 2013.287 c. - ISBN978-5-238-02358-8.

3. Фаттахова А.Р., Сарварова Р.Р., Чибугаева С.Г. Повышение эффективности использования основных средств организации // Молодой ученый. - 2015. - № 23.- С. 669-670. 